\title{
Competitive Enrollment Policies in Computing Departments Negatively Predict First-Year Students' Sense of Belonging, Self-Efficacy, and Perception of Department
}

\author{
An Nguyen \\ Harvey Mudd College \\ Claremont, CA, USA \\ anguyen@hmc.edu
}

\author{
Colleen M. Lewis \\ Harvey Mudd College \\ Claremont, CA, USA \\ lewis@cs.hmc.edu
}

\begin{abstract}
Enrollment in computing at the college level has skyrocketed, and many institutions have responded by enacting competitive enrollment processes. However, little is known about the effects of enrollment policies on students' experiences. To identify relationships between those policies and students' experiences, we linked survey data from 1245 first-year students in 80 CS departments to a dataset of department policies. We found that competitive enrollment negatively predicts first-year students' perception of the computing department as welcoming, their sense of belonging, and their self-efficacy in computing. Both belonging and self-efficacy are known predictors of student retention in CS. In addition, these relationships are stronger for students without pre-college computing experience. Our classification of institutions as competitive is conservative, and false positives are likely. This biases our results and suggests that the negative relationships we found are an underestimation of the effects of competitive enrollment.
\end{abstract}

\section{KEYWORDS}

competition; department policies; belonging; inclusion

\section{ACM Reference Format:}

An Nguyen and Colleen M. Lewis. 2020. Competitive Enrollment Policies in Computing Departments Negatively Predict First-Year Students' Sense of Belonging, Self-Efficacy, and Perception of Department. In The 51st ACM Technical Symposium on Computer Science Education (SIGCSE '20), March 11-14, 2020, Portland, OR, USA. ACM, New York, NY, USA, 7 pages. https: //doi.org/10.1145/3328778.3366805

\section{INTRODUCTION}

In the United States, computing fields are unbalanced in representation by race and gender with respect to the population $[25,32$, 36, 37]. This lack of diversity is not simply an issue of fairness [37]. Diversity in computing can help produce more insights and solutions to benefit society $[9,37]$. Additionally, there is a shortage of people to fill computing jobs [37], so it would be economically

Permission to make digital or hard copies of all or part of this work for personal or classroom use is granted without fee provided that copies are not made or distributed for profit or commercial advantage and that copies bear this notice and the full citation on the first page. Copyrights for components of this work owned by others than the author(s) must be honored. Abstracting with credit is permitted. To copy otherwise, or republish, to post on servers or to redistribute to lists, requires prior specific permission and/or a fee. Request permissions from permissions@acm.org.

SIGCSE '20, March 11-14, 2020, Portland, OR, USA

(c) 2020 Copyright held by the owner/author(s). Publication rights licensed to ACM. ACM ISBN 978-1-4503-6793-6/20/03 ..\$15.00

https://doi.org/10.1145/3328778.3366805 beneficial for groups currently underrepresented in computing to be proportionally represented.

One way to address patterns of underrepresentation in the workforce is to focus on retaining women and underrepresented minority students at the undergraduate level. Research has found that a low sense of belonging [14, 23], low self-efficacy [20,30], and a low growth mindset $[10,17,22]$ are associated with leaving computing.

We hypothesize that certain computing department policies could negatively impact these outcomes and ultimately lead to attrition. Specifically, we look at competitive enrollment, where admission to a computing major requires certain grades or an application. This may be a policy many computing departments are considering to manage enrollment pressures [29,41]. We also look at the inability to pass out of CS1, "a first course introducing students to programming fundamentals" [16], with prior computing experience.

We measured the outcomes of interest using survey data from first-year students enrolled in a computing course at one of 80 institutions in the United States and Canada. Using institution websites, we collected information about their policies. We then ran regressions to predict the outcomes of interest for students based on the policies of their computing department.

Controlling for race and gender, we found that for students without prior experience, competitive enrollment was a significant negative predictor of sense of belonging and self-efficacy. For students with prior computing experience, competitive enrollment was a significant negative predictor of a perception of department as welcoming. Inability to pass out of CS1 was not a significant predictor of any outcome of interest. Neither department policy was a statistically significant predictor of a students' growth mindset.

\section{PREVIOUS RESEARCH}

Competition is a theme across a variety of research focused on the experience of post-secondary students in STEM [3, 4, 13, 22, 26, 35, 36]. For example, Seymour and Hewitt [35] highlight the negative impact of introductory weed-out courses in STEM across five institutions. Shapiro and Sax describe how competitive educational environments may more strongly discourage women than men from persisting in STEM [36].

In computing, the seminal work Unlocking the Clubhouse [26] described undergraduate women's experiences with competition at Carnegie Mellon University. Lewis and colleagues described how students' negative experiences of competition at an institution with competitive enrollment negatively influenced their decision to persist in CS [22]. Barker and colleagues observed introductory 
college CS classrooms for over 385 hours and found that competition was often prioritized over cooperation [3, 13].

Taken together, weed-out courses and other competitive academic processes appear to negatively impact students' experiences $[3,13,22,26,34]$. However, these patterns have generally been identified at individual, research-intensive, $\mathrm{PhD}$-granting institutions $[3,13,22,26]$ and have not been systematically documented across a wider range of institutions.

Next, we briefly describe research showing that persistence in STEM and computing can be predicted by a student's sense of belonging [14, 23, 31], self-efficacy [20, 30], and growth mindset $[10,17,22]$. We then discuss research related to two department policies: competitive enrollment and passing out of CS1.

\subsection{Belonging}

A sense of academic belonging is "the subjective feeling of fitting in and being included as a valued and legitimate member of an academic discipline" [7]. In general, a desire to belong is a primary motivator in humans [5], and a strong sense of academic belonging is associated with increased academic achievement $[14,40]$ and academic interest [27]. Studies have also shown that a strong sense of belonging is associated with persistence in STEM [14]. In computing, Lewis et al. found that, even when controlling for self-efficacy, students' sense of belonging in computing predicted persistence in computing [23]. They also found, similar to findings in related work [24, 31], that women had a lower sense of belonging than men [23]. Previous research has also found evidence that Black and Latinx students have lower sense of belonging than White students [31].

\subsection{Self-efficacy}

Self-efficacy is "belief about one's ability to plan for and execute steps necessary for future success" [7]. In multiple fields, selfefficacy has been found to be a strong explanatory factor behind what decisions one makes and how long one persists with an action [2]. In STEM, research has found that students' belief in their ability to succeed academically is a predictor of academic achievement and persistence [20, 30]. Previous research has found that within STEM $[19,38]$ and computing [7, 19], women reported lower confidence in their ability to succeed than men.

\subsection{Growth Mindset}

A growth mindset is the belief that skills and intelligence can be developed through hard work and strategic action [11]. In contrast, a fixed mindset is the belief that skills and intelligence are intrinsic qualities that cannot be changed [11]. A growth mindset has been found to be a predictor of higher academic achievement [12,17] and persistence $[17,22]$ in STEM. It has also been shown that women who have a growth mindset are more resistant to the effects of negative stereotypes about women in STEM [12]. On the other hand, women who have a fixed mindset are more likely to both struggle with learning in STEM fields and have a decreased sense of belonging in STEM [10].

\subsection{Competitive Enrollment}

Competition for major admission means that eventually some students will be excluded from the community, which may decrease students' sense of belonging [35]. Processes of excluding students may reinforce the idea that some students can and some students cannot learn CS (i.e., a fixed mindset $[3,13,22,35])$. In addition, competitive enrollment processes may increase student comparisons to peers or jockeying for status $[3,13,22]$ as students attempt to assess or affirm their ability to major in computing. Frequent comparisons to the most experienced students may decrease students' self-efficacy, which may then decrease students' sense of belonging. Again, this may be worse for students without prior experience. Competition for major admission may also lead to less collaboration between students [22], which could decrease students' sense of belonging.

Both the potential for decreasing students' sense of belonging and reinforcing a fixed mindset may be worse for students without prior experience, because they are more likely to be excluded. However, for those students who are admitted to the major, this process of competitive enrollment may ultimately increase their sense of belonging. Therefore, we include only first-year students, some of whom we expect have not yet been admitted to the major.

\subsection{Passing out of CS1}

Based upon their experiences at Harvey Mudd College, Alvorado et al. [1] advocate splitting introductory CS courses by experience, which can include allowing students to pass out of CS1 if applicable. Inability to pass out of CS1 may mean that more experienced students intimidate students with less experience [1, 3, 4, 13], which could decrease students' self-efficacy. A lower self-efficacy could lead to a lower sense of belonging, and both may be worse for students without prior experience. If experience is conflated with ability [3, 13], this may reinforce a fixed mindset about computing.

Students enrolling in CS1 with prior experience, who would otherwise pass out of the course, could lead to students taking CS1 without prior experience receiving worse instruction and lower grades [22]. For students without prior experience, receiving lower grades may decrease their self-efficacy and may then decrease their sense of belonging. Instruction may be inaccessible for students without prior experience [22], which can lead to decreased selfefficacy and a perception that learning CS requires innate ability.

\section{RESEARCH QUESTIONS AND HYPOTHESES}

We hypothesize that competitive enrollment and the inability to pass out of CS1 will cause first-year students to report a perception of the department as unwelcoming, a lower sense of belonging, lower self-efficacy, and a fixed mindset. We focus on first-year students because we assume they are most likely to be impacted by major declaration and CS1 policies. We also hypothesize that the relationship between the department policies and the students' experiences is stronger for first-year students without previous computing experience than for those with previous experience because they are at a disadvantage in competitive enrollment processes and may be intimidated by interacting with students with more experience.

Our research questions are as follows: 
- Do department policies for major and CS1 enrollment predict a perception of the department as unwelcoming, a lower sense of belonging, lower self-efficacy, and a fixed mindset among first-year students?

- Are these patterns different for students with and without prior computing experience?

We control for race and gender because previous research has found them to be known predictors of sense of belonging [21, 23, 40], selfefficacy [7, 38, 40], and growth mindset [10].

\section{DATA}

Before accessing the survey data, we preregistered the study ${ }^{1}$, recording our research questions, hypotheses, and variables of interest [28].

\subsection{Sample}

Data was collected by the Computing Research Association's Center for Evaluating the Research Pipeline using a survey open for three months, starting in November 2018. 1,245 first-year students ${ }^{2}$ from 80 institutions took the survey. Of the first-year respondents, 513 were White ${ }^{3}, 586$ were Asian ${ }^{4}, 54$ were Black $^{5}$, and 92 were Latinx ${ }^{6}$. Our analysis excluded students who selected "American Indian/Alaska Native," "Native Hawaiian/Pacific Islander," "Arab/Middle Eastern," or "Something else" due to a low number of responses ( $\mathrm{N}<25$ for each category), as well as students who selected multiple options ( $\mathrm{N}=182$ students). About one third of the students were female, with the rest male ${ }^{7} .81 \%$ of students had prior computing experience ${ }^{8}$. The demographics of the respondents are summarized in Table 1.

Table 1: Summary of survey respondent demographics

\begin{tabular}{c|cccc|c|c}
\hline \hline & White & Asian & Black & Latinx & Female & Prior Exp. \\
\hline $\mathrm{N}$ & 513 & 586 & 54 & 92 & 447 & 1014 \\
$\%$ & 0.41 & 0.47 & 0.04 & 0.07 & 0.36 & 0.81 \\
\hline \hline
\end{tabular}

\footnotetext{
${ }^{1}$ The preregistration can be viewed here: osf.io/4znaq.

${ }^{2}$ There was no explicit survey question asking the student's year, so we classify students as first-year students if they selected that they entered the institution in 2018, and did not select that their expected graduation date was 2018, 2019, or 2020.

${ }^{3}$ We refer to students who selected "Caucasian/European/White" as "White"

${ }^{4}$ We refer to students who selected "East Asian (e.g., Chinese, Japanese, Korean)," "Southeast Asian (e.g., Cambodian, Vietnamese, Hmong, Filipino)," "South Asian (e.g., Indian, Pakistani, Nepalese, Sri Lankan)," or "Other Asian" as "Asian."

${ }^{5}$ We refer to students who selected "'African American/African/Black"" as "Black"

${ }^{6} \mathrm{We}$ refer to students who selected "Caribbean/Puerto Rican," "Mexican Ameri can/Chicano," or "Other Hispanic/Latino" as "Latinx." We use Latinx rather than Latino/a to avoid the assumption that someone identifies with only one of two genders. In the paper, we refer to "Latinx" as a racial group, but in the U.S. Latinx is more likely to be treated as ethnicity that is orthogonal to race.

${ }^{7}$ We dropped students who selected "Gender-queer/non-conforming" or "Something else" due to a low number of responses.

${ }^{8}$ We classify students as having prior experience if they selected any of the following: "Took an AP/Dual enrollment computer science course," "Learned a computer programming language," "Engaged in software or hardware related projects," "Took part in student groups related to computing," "Completed an online course related to computing (e.g., MOOC)," or "Attended a workshop or other training in computing (e.g., through your local library, community center, etc.)."
}

\subsection{Measures}

In addition to the demographic data from the survey (Section 4.1), students were asked about their perception of their computing department and faculty as welcoming (Section 4.2.1), their sense of belonging (Section 4.2.2), their self-efficacy in computing (see Section 4.2.3), and whether they believed computing ability was innate or learned (Section 4.2.4). The survey item responses and aggregate measures are summarized in Table 2. Our analysis (Section 5.1) uses these measures after they are normalized and mean-centered.

4.2.1 Perception of Department as Welcoming. Perception of the department as welcoming was measured by responses to the following survey items: I feel a sense of community in the computing department, The department cares about its students, The department is not very supportive of students (reverse coded) ${ }^{9}$. The items were under the heading, How do you feel about the environment of the department of your computing program? It was also measured using the survey item: Introductory course faculty are inclusive and supportive that was rated using the same options. We averaged the three responses to create an overall perception of department measure $\left(\right.$ Cronbach's alpha $=0.77^{10}$ ). If all four items were unranked, the student did not receive a value for the perception of department aggregate. If only a subset of the four items were unranked by a student, the mean of the ranked items was used.

4.2.2 Sense of Belonging in Computing. Sense of belonging in computing was measured by responses to the following survey items: $I$ feel like I belong in computing, I see myself as a computing person, and I feel like an outsider in computing (reverse coded). The survey stated, How much do you agree or disagree with the following statements? with each item rated on the same scale as in Section 4.2.1. To construct an overall sense of belonging measure, the mean of the items was calculated with missing data handled as described in Section 4.2.1 (Cronbach's alpha $=0.82$ ).

4.2.3 Self-Efficacy in Computing. Self-efficacy in computing was measured by responses to the following survey items: I am confident that I can...: complete an undergraduate degree in computing, pass my computing classes, learn the foundations and concepts of computing. Each item was rated on the same scale as in Section 4.2.1. To construct an overall self-efficacy measure, the mean of the items was calculated with missing data handled as described in Section 4.2.1 (Cronbach's alpha $=0.85$ ).

4.2.4 Fixed/Growth Mindset. Fixed/growth mindset was measured by responses to the following survey items: People have a certain amount of ability to learn computing, and they really can't do much to change it and Anyone has the ability to learn computing and be good at it (reverse coded). The survey stated, Please indicate the extent to which you disagree or agree with the following statements ${ }^{11}$. To construct an overall fixed/growth mindset measure, the mean of the items was calculated with missing data handled as described in Section 4.2.1 (Cronbach's alpha $=0.70)$.

\footnotetext{
${ }^{9}$ Items were rated using the following options: (1) Strongly disagree, (2) Somewhat disagree, (3) Neither agree nor disagree, (4) Somewhat agree, (5) Strongly agree.

${ }^{10}$ As stated in our preregistration, we planned to exclude composite measures with Cronbach's alphas less than 0.70 .

${ }^{11}$ Items were rated with the following options: (1) Strongly disagree, (2) Disagree, (3) Neither agree nor disagree, (4) Agree, (5) Strongly agree.
} 
Table 2: Summary statistics for measures described in Section 4.2, bold text indicates an aggregate measure.

\begin{tabular}{|c|c|c|c|}
\hline & Mean & SD & $\mathrm{N}$ \\
\hline $\begin{array}{l}\text { I feel a sense of community } \\
\text { in my department. }\end{array}$ & 3.57 & 1.03 & 1244 \\
\hline My department cares about its students. & 3.90 & 0.97 & 1243 \\
\hline $\begin{array}{l}\text { The department is not very supportive } \\
\text { of its students. (reverse coded) }\end{array}$ & 4.00 & 1.03 & 1240 \\
\hline $\begin{array}{l}\text { Introductory course faculty are/were } \\
\text { inclusive and supportive. }\end{array}$ & 4.17 & 0.90 & 1149 \\
\hline $\begin{array}{l}\text { Perception of Department } \\
\text { as Welcoming }\end{array}$ & 3.90 & 0.76 & 1245 \\
\hline I feel like I belong in computing. & 3.91 & 0.99 & 1244 \\
\hline I see myself as a computing person. & 4.03 & 0.92 & 1245 \\
\hline $\begin{array}{l}\text { I feel like an outsider in computing. } \\
\quad \text { (reverse coded) }\end{array}$ & 3.72 & 1.12 & 1244 \\
\hline Sense of Belonging & 3.89 & 0.87 & 1245 \\
\hline $\begin{array}{l}\text { I am confident I can complete an } \\
\text { undergraduate degree in computing. }\end{array}$ & 4.53 & 0.79 & 1245 \\
\hline I am confident I can pass my classes. & 4.46 & 0.76 & 1245 \\
\hline $\begin{array}{l}\text { I am confident I can learn the } \\
\text { foundations and concepts } \\
\text { of computing. }\end{array}$ & 4.54 & 0.67 & 1244 \\
\hline Self-Efficacy & 4.51 & 0.65 & 1245 \\
\hline $\begin{array}{l}\text { Anyone has the ability to learn } \\
\text { computing and be good at it. }\end{array}$ & 3.93 & 0.93 & 1244 \\
\hline $\begin{array}{l}\text { People have a certain amount of ability } \\
\text { to learn computing, and they really } \\
\text { can't change it. (reverse coded) }\end{array}$ & 3.64 & 1.06 & 1245 \\
\hline Growth Mindset & 3.79 & 0.88 & 1245 \\
\hline
\end{tabular}

\subsection{Institution Information}

The Computing Research Association's Center for Evaluating the Research Pipeline (CERP) provided the names of institutions that had 10 or more undergraduate responses to the survey. Using institution websites, we recorded, for each institution, if they had competitive enrollment and whether it was possible to pass out of the CS1 class with prior experience. Section 7 provides a discussion of the limitations of these classification methods.

4.3.1 Competitive Enrollment. An institution was coded as having competitive enrollment if students have to apply to become a computing major, or if a student needs to meet grade thresholds beyond passing to become a computing major. Some institutions have students choose majors when applying to the institution. These institutions were coded as having competitive enrollment if enrolled students have to apply or meet a grade threshold beyond passing to change to a computing major. Originally there were six codings, indicating the exact type of competitive enrollment (if any) and whether the policy was for declaring or changing major, but codings were collapsed to a binary classification due to low numbers of certain codings. Information was generally found in web pages about applying to the institution or on pages detailing majors offered by the computing department.
4.3.2 Passing Out of CS1. Any of the following qualified as being able to use prior experience to pass out of CS1: a statement that prior experience is an acceptable prerequisite for the next highest course, a mention of a programming exam that allowed bypassing of CS1, an alternate course pathway for students with prior experience that did not include CS1, or an indication that a certain score on the Advanced Placement Computer Science A exam or the Advanced Placement Computer Science Principles exam [8] provided credit for CS1. Information was found in CS course descriptions, computing department websites, and institution policies on AP credit.

While not included in analyses, this process relied on identifying the equivalent of CS1 at an institution. For this, we built on previous work that has attempted to define $[15,16]$ and identify [6] CS1 courses. Like Becker and Fitzpatrick [6], we identified CS1 courses based on online course descriptions and computing major requirements. Combining the definitions used by Guo [15] and Hertz [16], we defined a CS1 course as the first required course for CS majors, with no CS prerequisites [15], generally focusing on programming fundamentals [16]. We defaulted to selecting a CS courses with no prerequisites.

4.3.3 Interrater Reliability. Two independent coders separately coded each institution; neither had access to the other's codings. Based on the condensed categories, the two coders had moderate agreement [18] on competitive enrollment codings (Cohen's kappa $=0.45$ ) and almost perfect agreement [18] on codings regarding passing out of CS1 (Cohen's kappa $=0.81$ ). All disagreements were resolved by jointly revisiting the institution websites and discussing. The final codings are summarized in Table 3.

The two coders first coded 11 randomly selected institutions (10\% of institutions). The two coders agreed on their codings regarding passing out of CS1 for all institutions but one, and had moderate agreement on competitive enrollment codings after collapsing the categories (Cohen's kappa $=0.48$ ). They discussed any disagreements to clarify the procedure and repeated the process with another randomly-selected 11 institutions. The two coders agreed completely on their codings regarding passing out of CS1 for all eleven institutions (Cohen's kappa $=1.00$ ), and had substantial agreement [18] on competitive enrollment codings after collapsing the categories (Cohen's kappa $=0.65$ ).

Table 3: Summary of institution department policies

\begin{tabular}{lcccc}
\hline & \multicolumn{2}{c}{ Institutions } & \multicolumn{2}{c}{ Students } \\
& $\mathrm{N}$ & $\%$ & $\mathrm{~N}$ & $\%$ \\
\hline Competitive Enrollment & 24 & 0.30 & 637 & 0.51 \\
Inability to Pass Out of CS1 & 11 & 0.14 & 84 & 0.07 \\
Both & 1 & 0.01 & 3 & 0.00 \\
\hline
\end{tabular}

\section{METHODS}

The analysis employs multiple regression.

\subsection{Regression Models}

To answer the research questions, we estimate models of the form in Equation 1. $y_{s}$ is our outcome of interest $(y)$ for a particular student $(s)$. There are four outcomes of interest: perception of computing 
Table 4: Regressions predicting perception of department, sense of belonging, self-efficacy, and growth mindset

\begin{tabular}{|c|c|c|c|c|c|c|c|c|}
\hline & \multicolumn{2}{|c|}{ Perception of Dept. } & \multicolumn{2}{|c|}{ Sense of Belonging } & \multicolumn{2}{|c|}{ Self-Efficacy } & \multicolumn{2}{|c|}{ Growth Mindset } \\
\hline & with & without & with & without & with & without & with & without \\
\hline Competitive & $-0.27^{*}$ & -0.27 & 0.02 & $-0.35^{*}$ & $-0.19^{*}$ & -0.32 & -0.02 & 0.05 \\
\hline Enrollment & $(0.12)$ & $(0.16)$ & $(0.06)$ & $(0.17)$ & $(0.08)$ & $(0.21)$ & $(0.09)$ & $(0.21)$ \\
\hline Inability to & -0.16 & -0.06 & 0.08 & -0.02 & -0.13 & -0.33 & -0.09 & 0.06 \\
\hline Pass Out of CS1 & $(0.17)$ & $(0.28)$ & $(0.14)$ & $(0.17)$ & $(0.15)$ & $(0.53)$ & $(0.20)$ & $(0.32)$ \\
\hline Female & $\begin{array}{l}-0.01 \\
(0.08)\end{array}$ & $\begin{array}{l}-0.10 \\
(0.16)\end{array}$ & $\begin{array}{c}-0.61^{* * *} \\
(0.06)\end{array}$ & $\begin{array}{c}-0.58^{* * *} \\
(0.12)\end{array}$ & $\begin{array}{c}-0.39^{* * *} \\
(0.07)\end{array}$ & $\begin{array}{c}-0.49^{* *} \\
(0.18)\end{array}$ & $\begin{array}{l}0.19^{* *} \\
(0.07)\end{array}$ & $\begin{array}{l}-0.04 \\
(0.12)\end{array}$ \\
\hline Asian & $\begin{array}{l}-0.03 \\
(0.08)\end{array}$ & $\begin{array}{c}0.07 \\
(0.19)\end{array}$ & $\begin{array}{c}-0.25^{* * *} \\
(0.05)\end{array}$ & $\begin{array}{l}-0.27 \\
(0.14)\end{array}$ & $\begin{array}{c}-0.27^{* * *} \\
(0.08)\end{array}$ & $\begin{array}{l}-0.33 \\
(0.18)\end{array}$ & $\begin{array}{c}-0.22^{* * *} \\
(0.06)\end{array}$ & $\begin{array}{l}-0.40^{*} \\
(0.16)\end{array}$ \\
\hline Black & $\begin{array}{l}-0.29 \\
(0.17)\end{array}$ & $\begin{array}{l}-0.68^{*} \\
(0.27)\end{array}$ & $\begin{array}{c}-0.45^{* *} \\
(0.15)\end{array}$ & $\begin{array}{l}-0.52 \\
(0.33)\end{array}$ & $\begin{array}{c}-0.57^{* *} \\
(0.21)\end{array}$ & $\begin{array}{l}-0.59 \\
(0.42)\end{array}$ & $\begin{array}{c}0.02 \\
(0.15)\end{array}$ & $\begin{array}{l}-0.38 \\
(0.30)\end{array}$ \\
\hline Latinx & $\begin{array}{c}0.11 \\
(0.12)\end{array}$ & $\begin{array}{c}0.13 \\
(0.24)\end{array}$ & $\begin{array}{c}-0.40^{* * *} \\
(0.09)\end{array}$ & $\begin{array}{c}0.06 \\
(0.19)\end{array}$ & $\begin{array}{l}-0.16 \\
(0.10)\end{array}$ & $\begin{array}{l}-0.37 \\
(0.21)\end{array}$ & $\begin{array}{c}0.04 \\
(0.12)\end{array}$ & $\begin{array}{l}-0.33 \\
(0.31)\end{array}$ \\
\hline Constant & $\begin{array}{l}0.21^{*} \\
(0.09)\end{array}$ & $\begin{array}{c}0.01 \\
(0.14)\end{array}$ & $\begin{array}{c}0.48^{* * *} \\
(0.05)\end{array}$ & $\begin{array}{c}0.03 \\
(0.16)\end{array}$ & $\begin{array}{c}0.50^{* * *} \\
(0.05)\end{array}$ & $\begin{array}{c}0.20 \\
(0.16)\end{array}$ & $\begin{array}{c}0.05 \\
(0.08)\end{array}$ & $\begin{array}{c}0.24 \\
(0.16)\end{array}$ \\
\hline$N$ & 1014 & 231 & 1014 & 231 & 1014 & 231 & 1014 & 231 \\
\hline Schools & 79 & 56 & 79 & 56 & 79 & 56 & 79 & 56 \\
\hline Adj. R-sq & 0.02 & 0.01 & 0.13 & 0.12 & 0.08 & 0.07 & 0.01 & 0.01 \\
\hline
\end{tabular}

department as welcoming, sense of belonging in computing, selfefficacy in computing, and growth mindset in computing.

Equation 1. Regression model.

$$
\begin{aligned}
y_{s}=\beta_{0} & +\beta_{1} \text { compEnroll }_{s}+\beta_{2} \text { noPassOut }_{s}+\beta_{3} \text { female }_{s} \\
& +\beta_{4} \text { asian }_{s}+\beta_{5} \text { black }_{s}+\beta_{6} \text { latinx }_{s}+\epsilon_{s}
\end{aligned}
$$

There are dummy variables indicating, for each school, whether there is competitive enrollment (compEnroll) and if students are unable to pass out of a CS1 course with prior programming experience (noPassOut). There is also a series of dummy variables indicating whether students are female (reference group: male students) and Asian, Black, or Latinx (reference group: White students). $\epsilon_{s}$ is an error term. Models are estimated based first on the subset of first-year students with prior computing experience and then the subset of first-year students without prior computing experience. Like related research, we cluster our standard errors by institution [21].

\subsection{Hypotheses}

5.2.1 Hypothesis 1: Coefficients will be negative for competitive enrollment and inability to pass out of CS1. We hypothesize that (a) a competitive enrollment policy and $(b)$ the inability to pass out of CS1 predict a significantly lower $y$ for each outcome of interest: perception of department as welcoming, sense of belonging, selfefficacy, or growth mindset. In terms of our model (see Equation 1), we hypothesize that, in all regressions, $\beta_{1}$ and $\beta_{2}$, the coefficients for competitive enrollment and the inability to pass out of CS1, are oth negative.

5.2.2 Hypothesis 2: Coefficients will be lower for students without prior experience. We also hypothesize that the department policies have a larger, negative relationship with the outcomes of interest for students without prior experience. In terms of our model, we hypothesize that the values of $\beta_{1}$ and $\beta_{2}$ are lower in the regression for students without prior experience than in the regression for students with prior experience.

\section{RESULTS}

The results of all regressions are shown in Table 4. All outcomes of interest are normalized and mean-centered.

Our study replicates previous research that found that within STEM fields female students have a significantly lower sense of belonging [23, 24, 31] and lower self-efficacy [7, 38] than male students. We also replicate previous results that found that Black and Latinx students have a lower sense of belonging [31, 40] and lower self-efficacy [40] than White students. Low values for all of those outcomes of interest have previously been found to be associated with attrition from the field [14, 20, 23, 30, 31].

The inability to pass out of CS1 does not significantly predict any of the outcomes of interest. Table 5 and Sections 6.1-6.4 summarize 
the results from our two hypotheses for each outcome of interest for competitive enrollment policies.

Table 5: Does competitive enrollment negatively predict outcomes (Hypothesis $\mathbf{1}$ ) and is the magnitude greater for students without prior experience (Hypothesis 2)

\begin{tabular}{lcc}
\hline \hline & Hypothesis 1 & Hypothesis 2 \\
\hline Perception of the Dept. & Yes & No \\
Sense of Belonging & No & Yes \\
Self-Efficacy & Yes & Yes \\
Growth Mindset & No & No \\
\hline \hline
\end{tabular}

\subsection{Perception of Department}

When predicting students' perception of the computing department as welcoming, the coefficient for competitive enrollment is negative for students with and without prior experience, as hypothesized. However, competitive enrollment is only significant predictor for students with prior experience. The coefficient for competitive enrollment is identical in regressions on both students with and without prior experience $\left(\beta_{1}=-0.27\right)$. Contrary to our hypothesis, this does not seem to differ between students with and without prior experience.

\subsection{Sense of Belonging}

The coefficient for competitive enrollment predicting sense of belonging is positive for students with prior experience and negative for students without prior experience. Competitive enrollment is only a significant predictor for students without prior experience.

\subsection{Self-Efficacy}

When predicting self-efficacy in computing, the coefficients for competitive enrollment is negative for both regressions, as hypothesized. Competitive enrollment is only a significant predictor for students with prior experience. Our second hypothesis, that the coefficient in the regression for students without prior experience would be lower than in the regression for students with prior experience, is correct for both department policies.

\subsection{Growth Mindset}

When predicting a growth mindset in computing, the coefficients for competitive enrollment is negative for students with prior experience and positive for students without prior experience. Thus our second hypothesis, that the coefficient in the regression for students without prior experience would be lower, is incorrect. Competitive enrollment is not a significant predictor in either regression.

\section{LIMITATIONS AND FUTURE WORK}

The data used for this study were cross sectional, so we cannot demonstrate causality for our model. We cannot rule out other factors that may be correlated with both the department policies and students' reported experiences. For example, competitive enrollment policies may attract students who differ in other ways that determine their selection of an institution. Future work could look at schools before and after changing their enrollment policies.

Due to low numbers of responses, we were forced to ignore several racial groups and genders beyond "male" and "female." Additionally, we did not investigate how gender and race interact in influencing our outcomes of interest.

The inability to pass out of CS1 was not significant in any of the models, but this may be because the sample was too small. Only 87 students were at one of 12 institutions where students were unable to pass out of CS1. It is also unclear from institution websites to what degree students are encouraged to pass out of CS1. If students with experience still take CS1, allowing students to skip CS1 may not provide the intended benefits [1].

It is difficult to tell how truly competitive some of the enrollment policies are. It may be common knowledge within the institution that applying for a computing major is a formality or a truly competitive process, but that information cannot be found on institution websites. Our classification of institutions as competitive is conservative, and false positives are likely. For example, for consistency, we classified the University of California, San Diego as having competitive enrollment. However, the grade thresholds for eligibility were intended to be inclusive and therefore admission to the major is determined primarily by a lottery [39]. False positives bias our results, and suggest that the negative relationships we found are an underestimation of the effects of competitive enrollment.

Competitive enrollment, and limiting participation in general, has been described as one of four general responses of institutions to increasing enrollment in computing [29]. Other responses are using resources in new ways, growing programs and resources, and restructuring computing education within the institution [29]. Future work could compare competitive enrollment with these other responses and their relationship with student experiences.

In future work, we plan to interview faculty and administrators to more accurately classify department policies. Also, due to low numbers, we collapsed the codings for institutions using applications and grade thresholds. Future work could explore if there is a significant difference between these two policies. Additionally, we plan to examine how first year students' experiences change over time following a change in enrollment policy at an institution.

\section{CONCLUSION}

Controlling for race and gender, we found that for students without prior experience, competitive enrollment was a significant negative predictor of sense of belonging and self-efficacy. For students with prior computing experience, competitive enrollment was a significant negative predictor of a perception of department as welcoming. Previous research has found that low sense of belonging [23] and low self-efficacy [20,30] is associated with attrition, and competitive enrollment policies could be a contributor to attrition in computing. Inability to pass out of CS1 was not a significant predictor of any outcome of interest. Neither department policy was a statistically significant predictor of students' growth mindset. Departments should, and likely do, consider potential unintended consequences of strategies to manage enrollment pressures. This may be particularly important for students without prior CS experience or for groups underrepresented in computing [33]. 


\section{ACKNOWLEDGMENTS}

This research would not be possible without the work of Heather Wright and Burçin Tamer from the Computing Research Association's Center for Evaluating the Research Pipeline (CERP). The authors would also like to thank Kip Lim and Yeabtsega Birhane for their assistance. This work was funded by the National Science Foundation (1821136).

\section{REFERENCES}

[1] Christine Alvarado, Zachary Dodds, and Ran Libeskind-Hadas. 2012. Increasing Women's Participation in Computing at Harvey Mudd College. ACM Inroads 3, 4 (Dec. 2012), 55-64. https://doi.org/10.1145/2381083.2381100

[2] Albert Bandura. 1982. Self-efficacy mechanism in human agency. American psychologist 37, 2 (1982), 122.

[3] Lecia Jane Barker, Kathy Garvin-Doxas, and Michele Jackson. 2002. Defensive Climate in the Computer Science Classroom. In Proceedings of the 33rd SIGCSE Technical Symposium on Computer Science Education (SIGCSE '02). ACM, New York, NY, USA, 43-47. https://doi.org/10.1145/563340.563354

[4] Lecia J Barker, Melissa O'Neill, and Nida Kazim. 2014. Framing classroom climate for student learning and retention in computer science. In Proceedings of the 45th ACM technical symposium on Computer science education. ACM, New York, NY, USA, 319-324.

[5] Roy F Baumeister and Mark R Leary. 1995. The need to belong: desire for interpersonal attachments as a fundamental human motivation. Psychological bulletin 117, 3 (1995), 497.

[6] Brett A. Becker and Thomas Fitzpatrick. 2019. What Do CS1 Syllabi Reveal About Our Expectations of Introductory Programming Students? In Proceedings of the 50th ACM Technical Symposium on Computer Science Education (SIGCSE '19). ACM, New York, NY, USA, 1011-1017. https://doi.org/10.1145/3287324.3287485

[7] Jennifer M. Blaney and Jane G. Stout. 2017. Examining the Relationship Between Introductory Computing Course Experiences, Self-Efficacy, and Belonging Among First-Generation College Women. In Proceedings of the 2017 ACM SIGCSE Technical Symposium on Computer Science Education (SIGCSE '17). ACM, New York, NY, USA, 69-74. https://doi.org/10.1145/3017680.3017751

[8] College Board. 2019. AP at a Glance. (2019). https://apcentral.collegeboard.org/ about-ap/ap-a-glance

[9] Anesa Diaz-Uda, Carmen Medina, and Beth Schill. 2013. Diversity's new frontier: Diversity of thought and the future of the workforce.

[10] Carol S Dweck. 2007. Is Math a Gift? Beliefs That Put Females at Risk. In Why arenâĂŹt more women in science, Stephen J Ceci and Wendy M Williams (Eds.) American Psychological Association, Washington DC, Chapter 4, 47-55.

[11] Carol S. Dweck. 2008. Mindset: The new psychology of success. Random House Digital, Inc., New York, NY.

[12] Carol S Dweck. 2014. Mindsets and math/science achievement. Institute for Advanced Study, New York, NY.

[13] Kathy Garvin-Doxas and Lecia J. Barker. 2004. Communication in Computer Science Classrooms: Understanding Defensive Climates As a Means of Creating Supportive Behaviors. F. Educ. Resour. Comput. 4, 1 (March 2004), 1-18. https: //doi.org/10.1145/1060071.1060073

[14] Catherine Good, Aneeta Rattan, and Carol S Dweck. 2012. Why do women opt out? Sense of belonging and women's representation in mathematics. Fournal of personality and social psychology 102, 4 (2012), 700.

[15] Philip Guo. 2014. BLOG@ CACM. https://cacm.acm.org/blogs/blog-cacm

[16] Matthew Hertz. 2010. What Do "CS1" and "CS2" Mean?: Investigating Differences in the Early Courses. In Proceedings of the 41st ACM Technical Symposium on Computer Science Education (SIGCSE '10). ACM, New York, NY, USA, 199-203. https://doi.org/10.1145/1734263.1734335

[17] Catherine Hill, Christianne Corbett, and Andresse St Rose. 2010. Why so few? Women in science, technology, engineering, and mathematics. ERIC, Washington DC.

[18] J. Richard Landis and Gary G. Koch. 1977. The Measurement of Observer Agreement for Categorical Data. Biometrics 33, 1 (1977), 159-174. http: //www.jstor.org/stable/2529310

[19] Kathleen J. Lehman, Linda J. Sax, and Hilary B. Zimmerman. 2016. Women planning to major in computer science: Who are they and what makes them unique? Computer Science Education 26, 4 (2016), 277-298. https://doi.org/10. 1080/08993408.2016.1271536

[20] Robert W Lent, Steven D Brown, and Kevin C Larkin. 1986. Self-efficacy in the prediction of academic performance and perceived career options. Fournal of counseling psychology 33, 3 (1986), 265.

[21] Colleen Lewis, Paul Bruno, Jonathan Raygoza, and Julia Wang. 2019. Alignment of Goals and Perceptions of Computing Predicts Students' Sense of Belonging in Computing. In Proceedings of the 2019 ACM Conference on International Computing Education Research (ICER '19). ACM, New York, NY, USA, 11-19. https://doi.org/
$10.1145 / 3291279.3339426$

[22] Colleen M. Lewis, Ken Yasuhara, and Ruth E. Anderson. 2011. Deciding to Major in Computer Science: A Grounded Theory of Students' Self-assessment of Ability. In Proceedings of the Seventh International Workshop on Computing Education Research (ICER '11). ACM, New York, NY, USA, 3-10. https://doi.org/10.1145/ 2016911.2016915

[23] Karyn Lewis, Jane G. Stout, Noah Finkelstein, Steven J. Pollock, Akira Miyake, Geoff L. Cohen, and Tiffany A. Ito. 2017. Fitting in to Move Forward: Belonging, Gender, and Persistence in the Physical Sciences, Technology, Engineering, and Mathematics (pSTEM). Psychology of Women Quarterly (08 2017), 036168431772018. https://doi.org/10.1177/0361684317720186

[24] Karyn L. Lewis, Jane G. Stout, Noah D. Finkelstein, Steven J. Pollock, Akira Miyake, Geoff L. Cohen, and Tiffany A. Ito. 2017. Fitting in to Move Forward: Belonging, Gender, and Persistence in the Physical Sciences, Technology, Engineering, and Mathematics (pSTEM). Psychology of Women Quarterly 41, 4 (2017), 420-436. https://doi.org/10.1177/0361684317720186

[25] Jane Margolis. 2010. Stuck in the shallow end: Education, race, and computing. MIT Press, Cambridge, MA.

[26] Jane Margolis and Allan Fisher. 2003. Unlocking the clubhouse: Women in computing. MIT press, Cambridge, MA.

[27] Allison Master, Sapna Cheryan, and Andrew N Meltzoff. 2016. Computing whether she belongs: Stereotypes undermine girls' interest and sense of belonging in computer science. Journal of Educational Psychology 108, 3 (2016), 424.

[28] Brian A. Nosek, Charles R. Ebersole, Alexander C. DeHaven, and David T. Mellor. 2018. The preregistration revolution. Proceedings of the National Academy of Sciences 115, 11 (2018), 2600-2606. https://doi.org/10.1073/pnas.1708274114 arXiv:https://www.pnas.org/content/115/11/2600.full.pdf

[29] National Academies of Sciences, Engineering, and Medicine. 2018. Assessing and Responding to the Growth of Computer Science Undergraduate Enrollments. The National Academies Press, Washington, DC, Chapter 6 Institutional Strategies, 124-146. https://doi.org/10.17226/24926

[30] Frank Pajares and Dale H Schunk. 2001. Self-beliefs and school success: Selfefficacy, self-concept, and school achievement. Perception 11 (2001), 239-266.

[31] Linda J. Sax, Jennifer M. Blaney, Kathleen J. Lehman, Sarah L. Rodriguez, Kari L. George, and Christina Zavala. 2018. Sense of Belonging in Computing: The Role of Introductory Courses for Women and Underrepresented Minority Students. Social Sciences 7, 8 (2018). https://doi.org/10.3390/socsci7080122

[32] Linda J. Sax, Kathleen J. Lehman, Jerry A. Jacobs, M. Allison Kanny, Gloria Lim, Laura Monje-Paulson, and Hilary B. Zimmerman. 2017. Anatomy of an Enduring Gender Gap: The Evolution of WomenâĂŹs Participation in Computer Science. The fournal of Higher Education 88, 2 (2017), 258-293. https://doi.org/10.1080/ 00221546.2016 .1257306

[33] Linda J. Sax, Kathleen J. Lehman, and Christina Zavala. 2017. Examining the Enrollment Growth: Non-CS Majors in CS1 Courses. In Proceedings of the 2017 ACM SIGCSE Technical Symposium on Computer Science Education (SIGCSE '17). ACM, New York, NY, USA, 513-518. https://doi.org/10.1145/3017680.3017781

[34] Elaine Seymour and Nancy M. Hewitt. 1997. Talking about Leaving: Why Undergraduates Leave the Sciences. Westview Press, Boulder, CO.

[35] Elaine Seymour and Nancy M Hewitt. 2000. Talking about leaving: Why undergraduates leave the sciences. Westview press.

[36] Casey A Shapiro and Linda J Sax. 2011. Major selection and persistence for women in STEM. New Directions for Institutional Research 2011, 152 (2011), 5-18.

[37] C. Stephenson, A. Derbenwick Miller, C. Alvarado, L. Barker, V. Barr, T. Camp, C. Frieze, C. Lewis, E. Cannon Mindell, L. Limbird, D. Richardson, M. Sahami, E. Villa, H. Walker, and S. Zweben. 2018. Retention in Computer Science Undergraduate Programs in the U.S.: Data Challenges and Promising Interventions. Technical Report. ACM.

[38] Jane G Stout, Nilanjana Dasgupta, Matthew Hunsinger, and Melissa A McManus. 2011. STEMing the tide: using ingroup experts to inoculate women's self-concept in science, technology, engineering, and mathematics (STEM). Fournal of personality and social psychology 100, 2 (2011), 255.

[39] San Diego University of California. July 2019. CSE Capped Admissions Program. https://cse.ucsd.edu/undergraduate/admissions/cse-capped-major-status

[40] Gregory M Walton and Geoffrey L Cohen. 2007. A question of belonging: race, social fit, and achievement. Journal of personality and social psychology 92, 1 (2007), 82.

[41] Stuart Zweben and Betsy Bizot. 2019. 2018 CRA Taulbee Survey. Technical Report. CRA. 